American J. of Engineering and Applied Sciences 3 (4): 650-662, 2010

ISSN 1941-7020

(C) 2010 Science Publications

\title{
Flexural Behaviors of Damaged Full-Scale Highway Bridge Girder Strengthened by External Post Tension
}

\author{
Sayan Sirimontree and Jaruek Teerawong \\ Department of Civil Engineering, Khonkaen University, \\ Khonkaen, 40002, Thailand
}

\begin{abstract}
Problem statement: Prestressed Concrete (PC) I section girder with Reinforced Concrete (RC) topping slab has been widely applied to long span bridge girders for several years. A bridge girder is subjected to severe conditions caused by an aggressive environment and overloading. A crack can be initiated and propagate when the tensile stress exceeds the tensile strength of concrete due to overloading. Deterioration of the girder may be caused by a wide crack due to corrosion of the reinforcement and other mechanisms. Prestressing force and flexural stiffness (EI) of PC-I section girder are reduced depending on the level of overloading and the corresponding damage. Approach: Full scale tests of Type III AASHTO highway girder with a 20 $\mathrm{cm}$ thick RC topping slab were performed to study both the degradation process due to overloading and also the effects of external post-tension in the recovery of structural performance of a damaged highway PC bridge girder. Results: The results showed that degradation, loss of internal prestressing force in the PC-I girder and flexural stiffness of the composite girder depend directly on Damage Index (DI) expressed in terms of permanent deformation. External post tension with three levels of prestressing forces was applied to strengthen the damaged girder to recover its structural performance, flexural stiffness and strength. A simplified analytical model, verified by test results, was developed to predict flexural behaviors, loss of internal prestressing force and flexural stiffness of highway girder due to overloading and also structural performance of the strengthened girder. Conclusion: It was found that the required external prestressing force to effectively recover structural performance of a damaged girder depended directly on the damage index of the girder.
\end{abstract}

Key words: Moment-curvature, degradation, effective flexural rigidity, flexural stiffness, pretension, post-tension, external post-tension

\section{INTRODUCTION}

Flexural behavior of concrete girder can be expressed in terms of a moment curvature (M- $\phi)$ or load deflection (P- $\Delta$ ) diagram as shown in Fig. 1. Reinforced concrete has been developed and applied to flexural members for several decades. Flexural cracking, a crack width less than the permissible by the code of practice, can occur at service loading conditions in reinforced concrete members. This causes excessive deflection and wider cracks in long span RC structures. Sectional properties, for example cross sectional area and moment of inertia, change from the gross to cracked section. This problem is reduced when prestressed concrete has been applied. Cracking in the tension zone of the concrete section can be delayed by pre-compressed force which is produced by tensioning of the high strength reinforcing steel. A crack is generally not permitted at service loading conditions for PC members so gross or uncracked sectional properties remain unchanged.

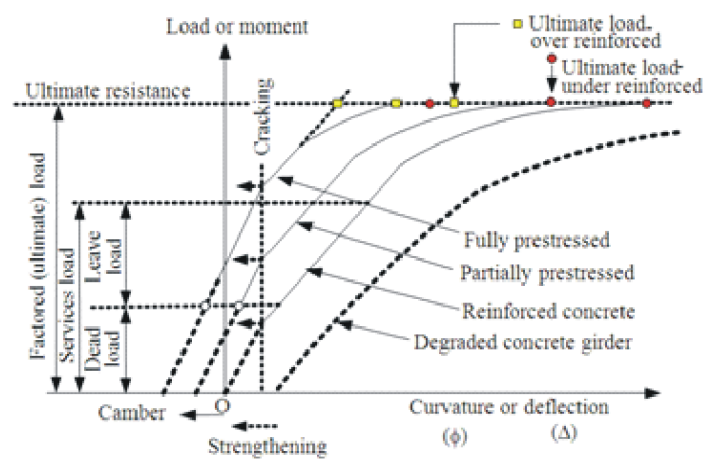

Fig. 1: Typical load deformation relationship of concrete girder (Naaman and Siriaksorn, 1979)

This pre-compressed force reduces short and long term deflection at the service loading stage in a PC girder. Overloading due to high traffic load on a highway girder may cause cracking and some permanent deformation, leading to loss of internal prestressing force and flexural rigidity or stiffness

Corresponding Author:Sayan Sirimontree, Department of Civil Engineering, Khonkaen University, Khonkaen, 40002, Thailand Tel: 66-2-5643001-9/Ext.3112 Fax: 66-2-5643001-9/Ext.303966-2-5643010 
(EI) of the damaged PC girder. Flexural behavior of highway girder can change from fully prestressed to partially or non-prestressed (RC) due to degradation with loss of prestressing force and flexural stiffness, caused by cracking and permanent deflection as shown in Fig. 1 (Naaman and Siriaksorn, 1979).

In this study, external post tension was applied to add prestressing force, to close the crack, reduce permanent deflection and enhance both flexural stiffness and strength of damaged full-scale test girder. Full scale tests of Type III AASHTO highway girder with a $20 \mathrm{~cm}$ thick RC topping slab were performed to study the degradation process due to overloading. The degree of damage of the overloaded girder was quantified in terms of Damage Index (DI), as structural performances were dependent on this index. External prestressing forces from external post tensioning were obtained to give the most effective amount of prestressing force to control a crack, permanent deformation, strength and stiffness of the damaged girder.

\section{MATERIALS AND METHODS}

Experimental studies: Flexural behavior of PC girder is clearly visible and understood on full size specimen, so pretension I girder conforming to ASSHTO Type III standard was chosen to test as a full-scale specimen, as shown by Fig. 2. The top slab, $20 \mathrm{~cm}$ thick and $1.60 \mathrm{~m}$ wide (half lane width), was cast in the full scale lab at Faculty of Engineering, Chulalongkorn University, Thailand. The concrete strength of pre-cast I girder and topping slab were designed to be 35 and $30 \mathrm{MPa}$ respectively. ASTM Grade 270 (specified breaking strength $=1890 \mathrm{MPa}$ ) low relaxation 7 wire strands with nominal diameter $12.7 \mathrm{~mm}$ were used for internal prestress of precast I girder. The total number of PC strands at mid span was 14 and some strands were debonded near the support to reduce tensile stress at the top fiber in the transfer stage. Reinforced concrete bar used for the topping slab conformed to Thai standard TIS SD40 (specified yield strength $=400 \mathrm{MPa}$ ). Total test span and shear span were 12.00 and $5.00 \mathrm{~m}$ respectively as shown in Fig. 2. The test girder was designed to standard truck load AASHTO-HS20-44.

A total of 5 tests with the same specimen was performed. Static load was gradually applied to the specimen by $2-2000 \mathrm{kN}$ hydraulic jacks from the elastic uncracked stage to inelastic crack stage in the 1 st test. Static load during loading and unloading was read by load cell while deformation data, strain and deflection, were scanned by a data acquisition unit and recorded by personal computer. The 2 nd test was performed in the same manner as the 1st test to illustrate the degradation processes which were quantified by permanent deformation and reduction of flexural rigidity expressed in terms of secant slope of load-deflection or moment-curvature relationship at the service loading stage. The degraded specimen after the 2 nd test was strengthened by $4-\phi 15.2 \mathrm{~mm}$ external strands with initial stress of $70 \%$ of breaking stress $\left(0.7 f_{p u}\right)$ before the 3rd test. Camber at mid span section due to external post tension was recorded and then the same process of testing was performed. It should be noted that anchorage and deviator for external post tension were adequately designed for various additional external prestressing forces in the 3rd-5th tests. External strands were removed after the 3 rd test specimen and replaced by 8 -and12 $\$ 15.2 \mathrm{~mm}$ diameter external strengthening strands with initial stress of $0.7 f_{p u}$ for the 4 th and 5 th tests respectively. Information of all tests is summarized in Table 1.
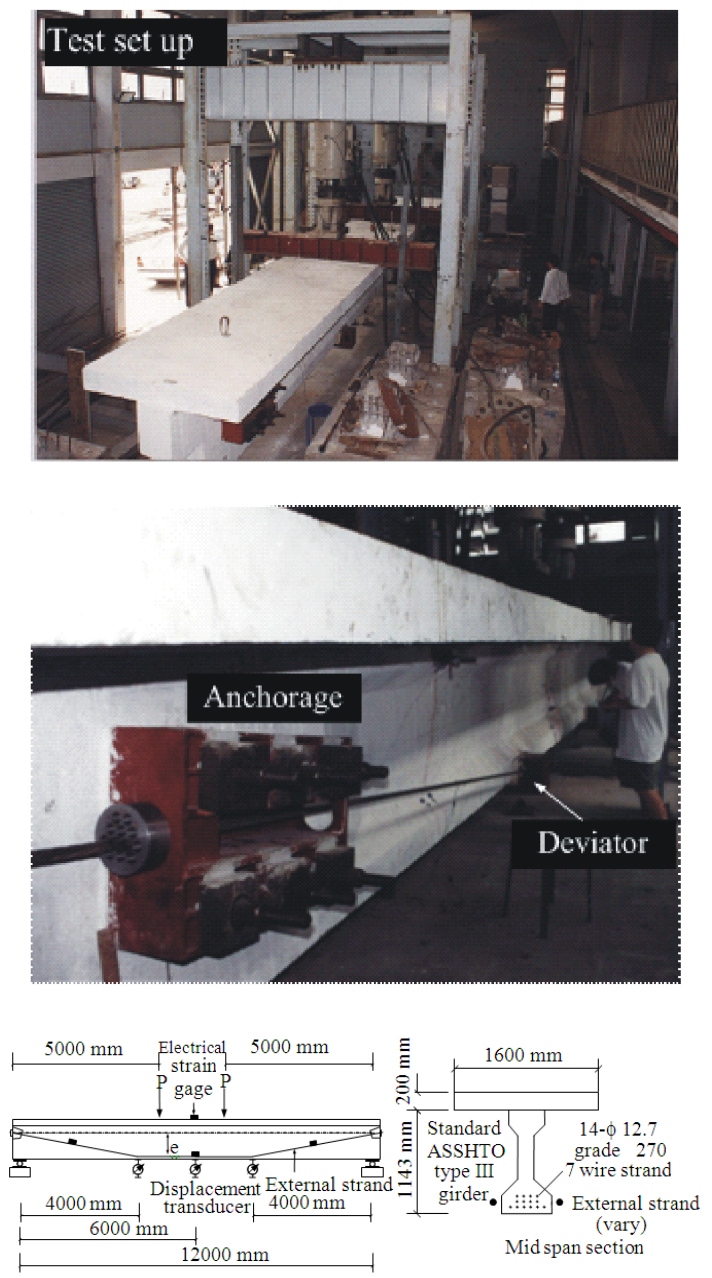

Fig. 2: Details and test set up of full-scale specimen 
Table 1: Information of all tests of the full scale specimen

\begin{tabular}{|c|c|c|c|c|c|}
\hline Test & $\begin{array}{l}\text { External } \\
\text { strand }\end{array}$ & $\begin{array}{l}\text { External prestressing } \\
\text { force }(\mathrm{kN})\end{array}$ & $\omega_{\text {psex }}$ & $\omega$ & Remark \\
\hline 1 & - & - & - & 0.040 & $\begin{array}{l}\text { Internal strand: } 14 \phi 12.7 \mathrm{~mm} \\
\text { Internal prestressing force: } 1820 \mathrm{kN}\end{array}$ \\
\hline 2 & - & - & - & 0.040 & $\begin{array}{l}\text { Internal steel ratio } p_{\mathrm{ps}}=\frac{\mathrm{S}_{\mathrm{ps}}}{\mathrm{bd}_{\mathrm{ps}}} \\
\text { External steel ratio } \mathrm{p}_{\mathrm{psex}}=\frac{\mathrm{A}_{\mathrm{psex}}}{\mathrm{bd}_{\mathrm{psex}}}\end{array}$ \\
\hline 3 & $4 \phi 15.2 \mathrm{~mm}$ & 750 & 0.017 & 0.057 & Internal reinforcing index $\omega_{\mathrm{ps}}=\mathrm{p}_{\mathrm{ps}} \frac{\mathrm{f}_{\mathrm{pu}}}{\mathrm{f}_{\mathrm{c}}^{\prime}}=0.04$ \\
\hline 4 & $8 \phi 15.2 \mathrm{~mm}$ & 1500 & 0.033 & 0.074 & External reinforcing index $\omega_{\mathrm{psex}}=\mathrm{p}_{\mathrm{psex}}=\frac{\mathrm{f}_{\mathrm{pu}}}{\mathrm{f}_{\mathrm{c}}^{\prime}}$ \\
\hline 5 & $12 \phi 15.2 \mathrm{~mm}$ & 2250 & 0.050 & 0.090 & Total reinforcing index $\omega=\omega_{\mathrm{ps}}+\omega_{\mathrm{psex}}$ \\
\hline
\end{tabular}

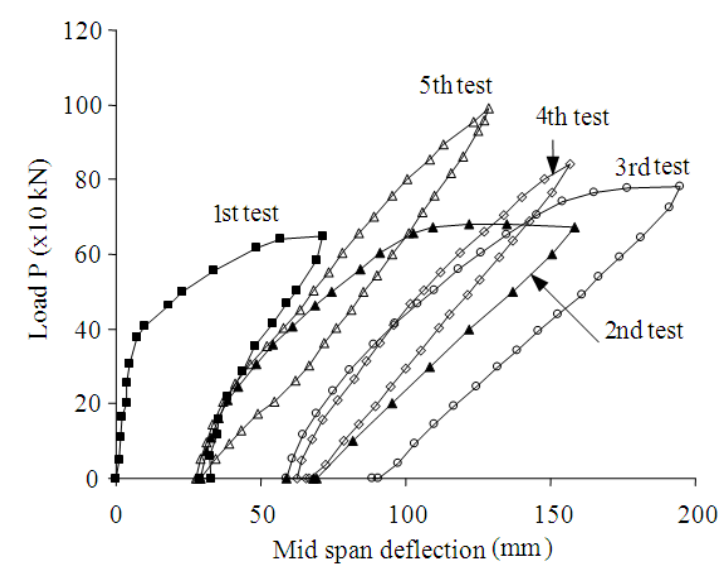

Fig. 3: Relationship of load and mid span deflection of all tests

Load and mid span deflection of all tests are summarized and illustrated by Fig. 3. It was found that permanent deflection, flexural stiffness and strength were recovered by external post-tension. The degradation due to overloading and effects of external post-tension are discussed in detail in the following topic. Crack patterns of the test girder are shown in Fig. 4.

Analytical models: The response of a slender beam, for which effects of shear deformation can be neglected, subjected to transverse applied load can be characterized by a differential equation for the flexural member as follows:

$\frac{d \theta}{d x}=\frac{d^{2} y}{d x^{2}}=\frac{M}{E I}=\frac{1}{\rho}=\phi=$ Curvature

where, curvature is the change of tangent slope $(\theta)$ per unit length and ratio of moment divided by flexural rigidity (EI) which can be proved by geometric theory and mechanics of materials.

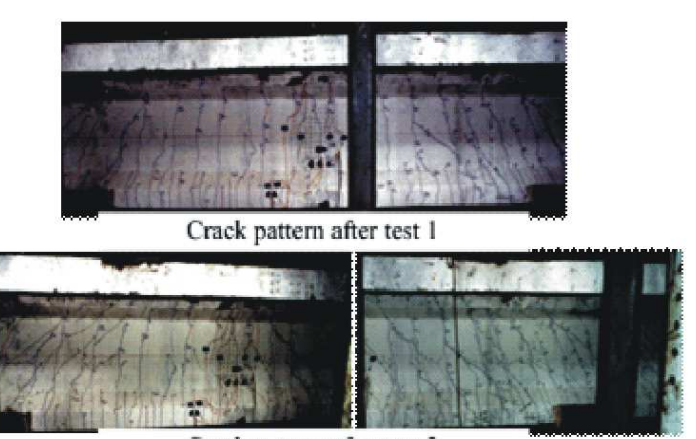

Crack pattern after test 2

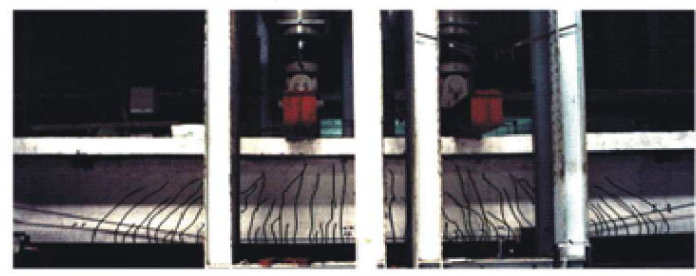

Crack pattern after test 3-5

Fig. 4: Crack pattern of test girder

Deflection of the beam can be calculated by direct integration to solve the differential equation but is complicated. Engineers in the past have developed simpler practical methods such as, conjugate beam, moment area and virtual study methods (Beer and Johnston, 1985; Hsieh, 1988). Moment area method can solve the differential equation of beam by taking the moment area of curvature diagram $[\mathrm{M} / \mathrm{EI}]$ about a certain point of the beam and using geometrical theory to calculate the deflection of beam subjected to the applied loading. The concrete section of the beam remains uncracked if the maximum tensile stress is less than the modulus of rupture or tensile strength of concrete, so the deflection of beam can be calculated using elastic theory, moment area method, based on gross or uncracked moment of inertia $\left(I_{g}\right)$. 


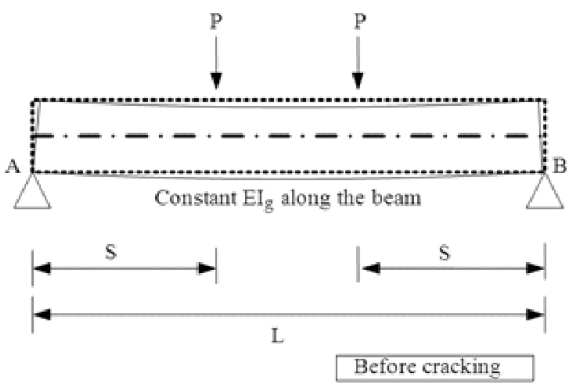

(a)

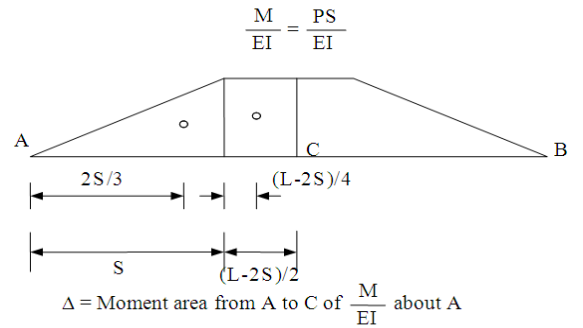

(b)

Fig. 5: Deflection of uncracked beam using moment area method

The similar shape of moment and curvature diagram along the beam can be expected (Fig. 5). Deflection of a beam subjected to symmetrical two point loading using moment area method is illustrated by Fig. 5 .

After cracking, the moment of inertia changes to cracked moment of inertia $\left(\mathrm{I}_{\mathrm{cy}}\right)$ so flexural rigidity becomes $\mathrm{EI}_{\mathrm{cy}}$ which varies for each step of increased load. In this stage, the shape of the bending moment and curvature diagram will not be similar but the moment area method is still applicable. The moment curvature diagram of concrete section for both gross and cracked sections must be constructed by the following assumptions:

- The beam is slender so shear deformation is not taken into account. This leads to the plane section remaining plane after bending and perfect bonding between steel (for PC and RC) and concrete(Compatibility condition)

- Summation of forces in concrete and steel are in equilibrium and the internal couple moment developed by the force in the concrete and steel is equal to the external applied moment (Equilibrium condition)

- The stress-strain relationship of concrete and steel must be known(Constitutive relation)

It should be noted that assumption 1) cannot be applied for an unbonded PC system due to the fact that the PC strands and concrete slip from each other in unbonded PC girder at high load level beyond the cracking or elastic stage. This leads to strain in unbonded PC steel of less than the concrete strain at the same location (incompatibility) leading to the loss of ultimate moment capacity compared to a bonded PC member. Large crack size but fewer cracks occur at the ultimate limit state for unbonded PC girder. Nonprestressed steel is generally provided to distribute cracks and increase strength and ductility of unbonded PC members. For and external post-tension girder, not only unbonded behavior of PC steel, but also second order effects, caused by incompatiblility between member deformation and the change of tendon profile and eccentricity ( $\mathrm{P}-\Delta$ effects), can occur at the inelastic stage with large deformation beyond the elastic stage (Alkhairi and Naaman, 1993; Matupayont, 1995; Tan and Ng, 1997; 1998; Diep and Umehara, 2002). This causes significant reduction of ultimate moment capacity of the external PC girder compared to bonded PC girder. Stress in unbonded external strands at the ultimate stage, depending on the geometry of tendon profile and shear span to effective depth ratio, was empirically proposed by previous researchers (Alkhairi and Naaman, 1993; Matupayont, 1995; Tan and Ng, 1997) for bonded PC steel as stress multiplied by bond reduction coefficient which is less than 1.0.

In this study, load and deformation at the end of each test were not large and secondary effects due to member deformation and unbonded behavior did not significantly affect the flexural behaviors, so the strain compatibility method can be applied approximately in moment curvature analysis of the girder section. This has been verified by test results which will be discussed in the next topic.

The cross section of PC girder was divided into 200 layers (or elements) so strain and stress at each layer could be computed by compatibility condition and constitutive relationships as shown in Fig. 6 . Calculation is made for a certain concrete strain in top fiber $\left(\varepsilon_{\text {top }}\right)$.

The material model (Stress-strain relationship) proposed by Popovics (1970) which can be used for both normal and high strength concrete, is shown in Fig. 7a and is used in this analytical method. A bilinear, elastic perfectly plastic model is used as the material model of RC steel as shown in Fig. 7b. The modified Ramberg and Osgood function, Eq. 2 and Fig. 7c, is used as the material model for PC steel (Mattock, 1979):

$$
\mathrm{f}_{\mathrm{ps}}=200 \times 10^{3} \varepsilon_{\mathrm{ps}}\left\{0.025+\frac{0.975}{\left[1+\left(118 \varepsilon_{\mathrm{ps}}\right)^{10}\right]^{0.1}}\right\} \leq 1860 \mathrm{Mpa}
$$

The relationship between strain at the top fiber concrete and steel can be calculated using the compatibility condition, so:

$\frac{\varepsilon_{\text {top }}}{\mathrm{c}}=\frac{\varepsilon_{\mathrm{s}}}{\mathrm{d}_{\mathrm{s}}-\mathrm{c}}=\frac{\Delta \varepsilon_{\mathrm{ps}}}{\mathrm{d}_{\mathrm{ps}}-\mathrm{c}}=\frac{\Delta \varepsilon_{\mathrm{psex}}}{\mathrm{d}_{\mathrm{psex}}-\mathrm{c}}$ 

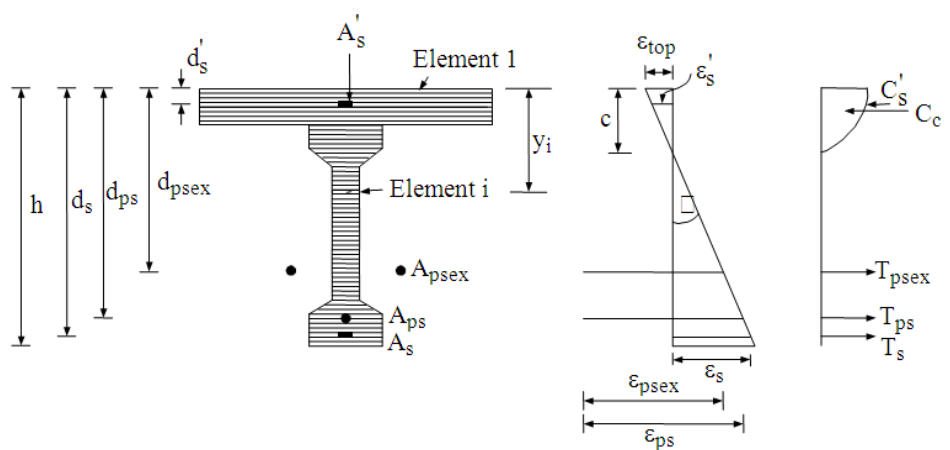

Fig. 6: Formulation of moment curvature relationship

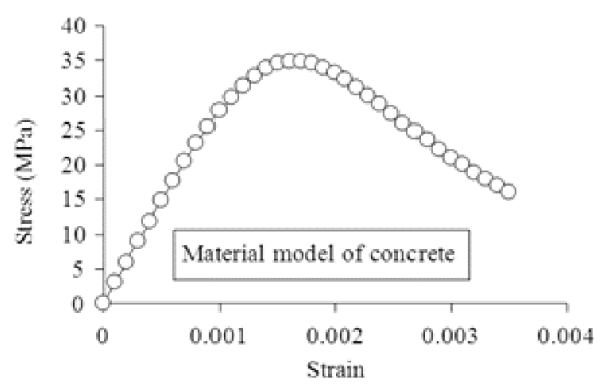

(a)

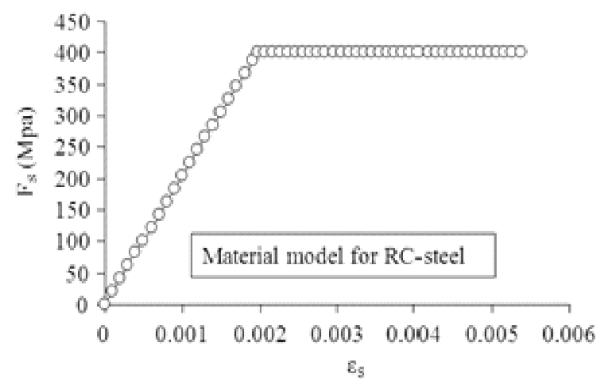

(b)

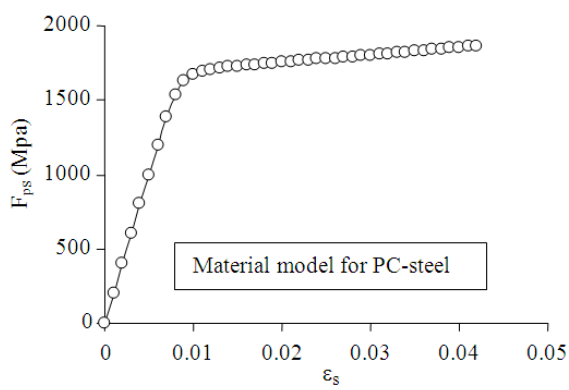

(c)

Fig. 7: Material model for concrete, RC and PC-steel

By fixing concrete strain at the top fiber and varying $\mathrm{c}$ (distance from top fiber to neutral axis), the strain in PC/RC steel can be calculated. Stress and resultant forces in concrete and steel can be evaluated by constitutive relationship (Fig. 7) as follows.

Using numerical techniques, $\mathrm{c}$ is varied until summations of forces in the horizontal direction are in equilibrium:

$$
\sum \mathrm{C}+\mathrm{T}=0, \mathrm{C}+\mathrm{C}_{\mathrm{s}}^{\prime}-\left(\mathrm{T}_{\mathrm{ps}}+\mathrm{T}_{\mathrm{psex}}+\mathrm{T}_{\mathrm{s}}\right)=0
$$

After the equilibrium stage, curvature can be computed by $\phi=\frac{\varepsilon_{\mathrm{top}}}{\mathrm{c}}$. The corresponding moment can be calculated by taking the moment of resultant forces about the top fiber of concrete section as follows:
$\mathrm{M}=\mathrm{M}_{\mathrm{ps}}+\mathrm{M}_{\mathrm{psext}}+\mathrm{M}_{\mathrm{s}}-\mathrm{M}_{\mathrm{c}}-\mathrm{M}_{\mathrm{s}}^{\prime}$

Symbols in Eq. 4 and 5 are summarized and described in Table 2.

The same procedure can be performed for any top fiber strain of concrete section so the corresponding moment and curvature can be computed. The moment curvature diagram of any section along the girder can be constructed so the load deflection diagram can be determined by the classical moment area method.

In this study, a simple method using the idea proposed by Branson (1977) was developed. Load and mid span deflection can be calculated approximately by the simplified method as shown in Fig. 8. 
Table 2: Descriptions of variables in Eq. 3-5

\begin{tabular}{ll}
\hline Term & Description \\
\hline $\mathrm{C}_{\mathrm{c}}=\int_{0}^{\mathrm{c}} \mathrm{f}_{\mathrm{c}} \mathrm{dA} \sum \mathrm{f}_{\mathrm{ci}} \Delta \mathrm{A}_{\mathrm{i}}$ & Compressive resultant force on concrete \\
$\mathrm{C}_{\mathrm{s}}^{\prime}=\mathrm{f}_{\mathrm{s}}^{\prime} \mathrm{A}_{\mathrm{s}}^{\prime}$ & Resulting compressive force carried by compression steel \\
$\mathrm{T}_{\mathrm{psex}}=\mathrm{f}_{\mathrm{psex}} \mathrm{A}_{\mathrm{psex}}$ & Resulting tensile force carried by external strand \\
$\mathrm{T}_{\mathrm{ps}}=\mathrm{p}_{\mathrm{p}} \mathrm{A}_{\mathrm{s}}$ & Resulting tensile force carried by internal strand \\
$\mathrm{T}_{\mathrm{s}}=\mathrm{f}_{\mathrm{s}} \mathrm{A}_{\mathrm{s}}$ & Resulting tensile force carried by non prestressed steel \\
$\mathrm{M}_{\mathrm{s}}^{\prime}=\mathrm{C}_{\mathrm{s}}^{\prime} \mathrm{d}_{\mathrm{s}}^{\prime}=\mathrm{f}_{\mathrm{s}}^{\prime} \mathrm{A}_{\mathrm{s}}^{\prime} \mathrm{d}_{\mathrm{s}}^{\prime}$ & Moment of resulting compressive force in compression steel about top fiber \\
$\mathrm{M}_{\mathrm{c}}=\mathrm{C}_{\mathrm{c}} \bar{y}_{\mathrm{c}}=\sum \mathrm{y}_{\mathrm{i}} \mathrm{f}_{\mathrm{ci}} \Delta \mathrm{A}_{\mathrm{i}}$ & Moment of resulting compressive force in concrete about top fiber \\
$\mathrm{M}_{\mathrm{psex}}=\mathrm{T}_{\mathrm{psex}} \mathrm{d}_{\mathrm{psex}}=\mathrm{f}_{\mathrm{psex}} \mathrm{Apsex}_{\mathrm{psex}} \mathrm{d}_{\mathrm{psex}}$ & Moment of resulting tensile force in external strand about top fiber \\
$\mathrm{M}_{\mathrm{ps}}=\mathrm{T}_{\mathrm{ps}} \mathrm{d}_{\mathrm{ps}}=\mathrm{f}_{\mathrm{ps}} \mathrm{A}_{\mathrm{ps}} \mathrm{d}_{\mathrm{ps}}$ & Moment of resulting tensile force in internal strand about top fiber \\
$\mathrm{M}_{\mathrm{s}}=\mathrm{T}_{\mathrm{s}} \mathrm{d}_{\mathrm{s}}=\mathrm{f}_{\mathrm{s}} \mathrm{A}_{\mathrm{s}} \mathrm{d}_{\mathrm{s}}$ & Moment of resulting tensile force in nonprestressed steel about top fiber \\
\hline
\end{tabular}

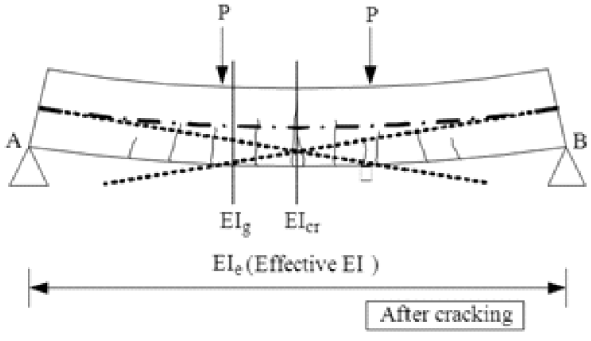

(a)

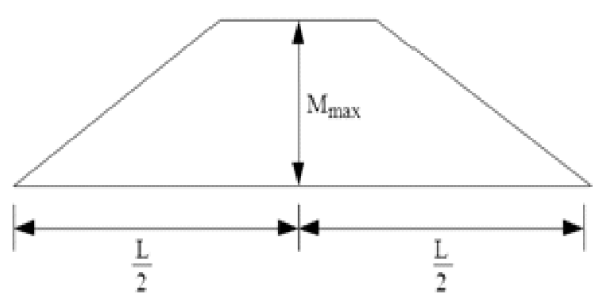

(b)

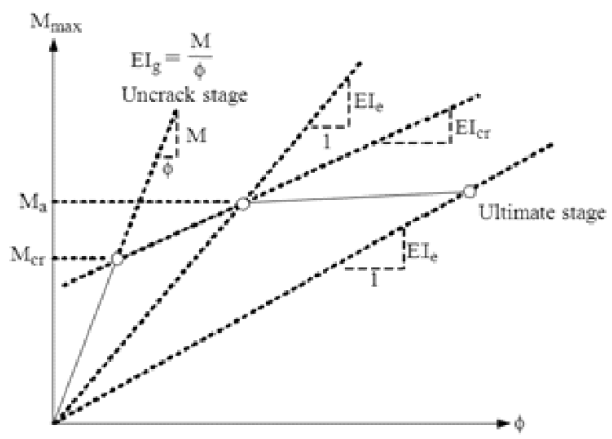

(c)

Fig. 8: Concept of effective flexural rigidity

Branson (1977) proposed a simplified equation for calculation of deflection after the cracking stage of RC beams at service loading stage. Since the use of such a distribution of EI values along the beam would make the deflection calculation tedious, an overall average of effective EI is used:

$I_{e}=\left(\frac{M_{c r}}{M_{a}}\right)^{3} I_{g}+\left[1-\left(\frac{M_{c r}}{M_{a}}\right)^{3}\right] I_{c r}$

Where:

$\mathrm{I}_{\mathrm{e}} \quad=$ The effective moment of inertia

$\mathrm{I}_{\mathrm{cr}}=$ The cracked moment of inertia

$\mathrm{I}_{\mathrm{g}}=$ The gross moment of inertia

$\mathrm{M}_{\mathrm{cr}}=$ The cracking moment

$\mathrm{M}_{\mathrm{a}}=$ The maximum moment where

$\mathrm{I}_{\mathrm{e}}=$ Calculated
$\mathrm{M}_{\mathrm{a}}=$ The maximum moment at mid span for $\mathrm{a}$ simply supported beam

Deflection can be calculated by elastic theory using effective moment of inertia or effective flexural rigidity $\left(\mathrm{EI}_{\mathrm{e}}\right)$. This concept can be represented by Fig. 8. The tangent slope of the M- $\phi$ diagram before cracking represents gross flexural rigidity $\left(\mathrm{EI}_{\mathrm{g}}\right)$ while the tangent slope after cracking represents cracked flexural rigidity $\left(\mathrm{EI}_{\mathrm{cr}}\right)$. Secant slope (from $0-\mathrm{M}_{\mathrm{a}}$ ), for which deflection is calculated, represents average effective flexural rigidity $\left(\mathrm{EI}_{\mathrm{e}}\right)$. This means that cracked or uncracked section properties and tension stiffening caused by concrete between cracks is accounted for in $\mathrm{EI}_{\mathrm{e}}$. Extending this concept beyond the service loading stage is used by the authors in the simplified method.

The moment curvature relationship of the mid span section was first constructed. Before cracking of 
a PC girder section, deflection can be obtained by elastic theory using gross flexural rigidity $\left(\phi=\frac{\mathrm{M}}{\mathrm{EI}_{\mathrm{g}}}\right)$.

After cracking of the concrete section, deflection was calculated at each step of loading for which $\mathrm{EI}_{\mathrm{g}}$ is changed to effective flexural rigidity $\left(\mathrm{EI}_{\mathrm{e}}\right) . \mathrm{EI}_{\mathrm{e}}$ lies between the extreme cases, $\mathrm{EI}_{\mathrm{g}}$ (gross flexural rigidity) and $\mathrm{EI}_{\mathrm{cr}}$ (cracked flexural rigidity), due to tension stiffening caused by concrete between adjacent cracks. Using this concept, mid span deflection can be computed by the following equation:

$$
\Delta=\mathrm{k} \phi \mathrm{L}^{2}
$$

Where:

$$
\begin{aligned}
\varphi=\frac{\mathrm{M}}{\mathrm{EI}} & =\text { Curvature } \\
\mathrm{L} & =\text { Span length } \\
\mathrm{M} & =\text { The maximum bending moment } \\
\mathrm{EI} & =\text { Calculated } \\
\mathrm{k} & =\text { Constant depending on loading pattern }
\end{aligned}
$$

For a simply supported beam subjected to two point load, deflection can be calculated by means of the moment area method as follows (Fig. 8):

$$
\Delta=\frac{1}{2} \phi S\left(\frac{2 \mathrm{~S}}{3}\right)+\phi\left(\frac{\mathrm{L}-2 \mathrm{~S}}{2}\right)\left(\mathrm{S}+\frac{\mathrm{L}-2 \mathrm{~S}}{4}\right)
$$

The shear span in the two point loading tests of this study was $\mathrm{S}=5.00 \mathrm{~m}$ while the test span was $\mathrm{L}=12.00 \mathrm{~m}$, so $\mathrm{S}=0.4167 \mathrm{~L}$. Deflection at mid span can be calculated approximately by Eq. 8 as follows:

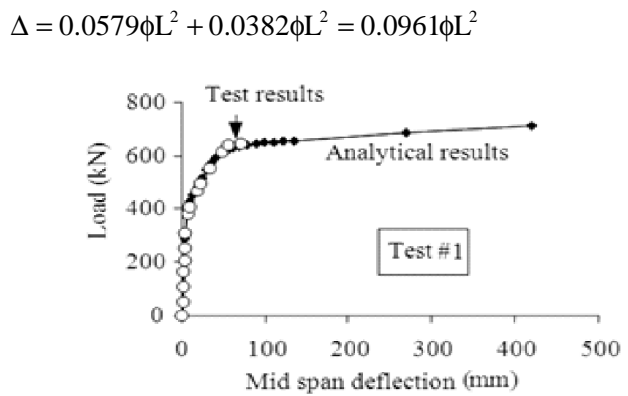

(a)

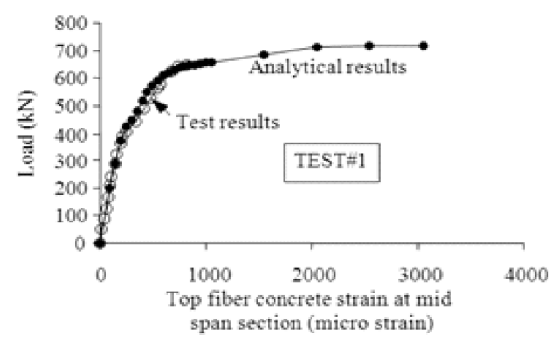

(c)

$$
\mathrm{k}=0.0961
$$

The simplified analytical model which has been developed was verified by the experimental results.

\section{RESULTS AND DISCUSSION}

The analytical model was verified by the original girder test results, load-mid span deflection and loadtop fiber strain at mid span section relationship, as shown by Fig. 9. It was found that there was good agreement between the 1st test and the analytical results. In the 2nd test, internal prestressing force was adjusted in the analytical model to give the best agreement with experimental results as shown by Fig. 9 because the damage index changed for each test. The remaining internal prestressing force before the 2nd test was approximately $50 \%$ of the original force. Initiation, propagation and accumulation of cracking led to permanent deformation after the 1 st test of the highway composite girder. This caused accumulated degradation of the previously tested girder leading to reduction of initial prestressing force and flexural stiffness expressed in terms of effective flexural rigidity in the next test of the specimen. Effective flexural rigidity of the test girder can be calculated by the secant slope of the moment-curvature or load-mid span deflection curve using Eq. 9:

$\mathrm{EI}_{\mathrm{e}}=\frac{\mathrm{M}}{\phi}=\frac{\mathrm{PS}}{\frac{\Delta}{\mathrm{kL}^{2}}}=\frac{\mathrm{PSkL}^{2}}{\Delta}$

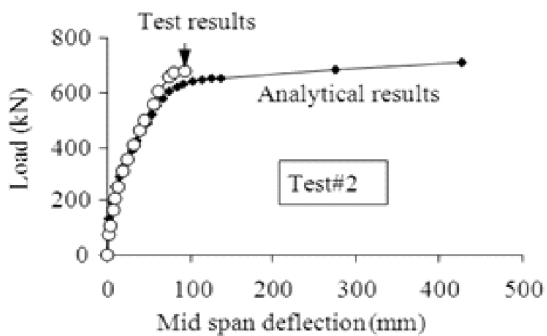

(b)

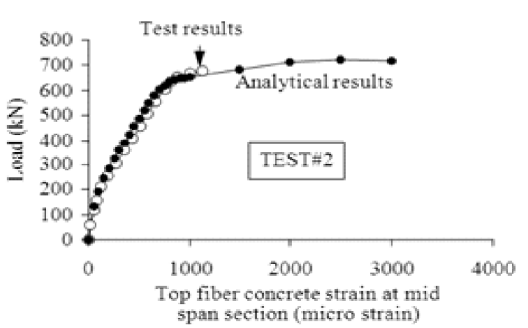

(d)

Fig. 9: Load-deformation relationship of Tests 1 and 2 
In this study, flexural rigidity was calculated at the cracking load of the original undamaged specimen and at the same load for the damaged and strengthened specimen. Initial prestressing force produced by internal strands in the pre-cast I girder reduced depending on the level of damage of the previous test specimen. The level of damage was quantified by Damage Index (DI) expressed in terms of permanent deformation divided by crack deformation of original undamaged girder as shown by the following equation:

$$
\mathrm{DI}=\frac{\Delta_{\mathrm{p}}}{\Delta_{\mathrm{cr}}}=\frac{\phi_{\mathrm{p}}}{\phi_{\mathrm{cr}}}
$$

After external post-tensioning permanent deformation was reduced by external prestressing force thus strengthening the damaged girder before the 3rd-5th tests. It was found from the results of all the tests, as shown in Fig. 3, that flexural stiffness due to damage caused by overloading could be recovered by external post-tensioning depending on the level of external prestressing force and level of damage of the test girder. Flexural strength was significantly increased by additional PC strands of external post-tensioning. The remaining internal prestressing force after each test could not be measured directly since electrical strain gages were not attached to internal strands. After cracking, strain data would not be reliable due to the redistribution of strain in the concrete and the PC strands between adjacent stabilized cracks. Strain in PC strands at the stabilized crack section was increased by the applied load due to deboning of concrete and strands. However, strain in the bonded PC strands between the stabilized cracked sections could not increase to more than the cracking strain of concrete at the same location (Park and Paulay, 1975). Initiation and location of the first crack was generally random and could not be predicted accurately so the strain in the internal strands monitored by electrical strain gage was reliable only before the first cracking of concrete in the tension zone of the PC girder.

Strain data from the external strands for each test of the strengthened girder could be measured accurately at each step of loading since they were not bonded to the surrounding concrete. After adjusting internal prestressing force in the analytical model to account for changes that occurred in the earlier tests, the load-mid span deflection relationship of the strengthened girder in the 3rd-5th tests was calculated and shown in Fig. 10. Load-stress for internal and external PC strands from both test and analytical results are expressed by Fig. 11. It should be noted that initial stress in the internal strands in the analytical model can have a minus value since damage and permanent deformation of the test girder was recovered by the high force from external posttensioning. This force probably caused initial compressive stress in the internal strands in the analytical model.

It can be seen from test and analytical results in Fig. 9 and 10 that maximum deformation in each test was much lower than the predicted ultimate deflection. So the significance of both unbonding and the second order effect (P- $\Delta$ effect) due to incompatibility between member deformation and external tendon profile in post-cracking or inelastic stage were low. Therefore, they can be neglected in the prediction of flexural behavior of the test girder by the simplified analytical model.

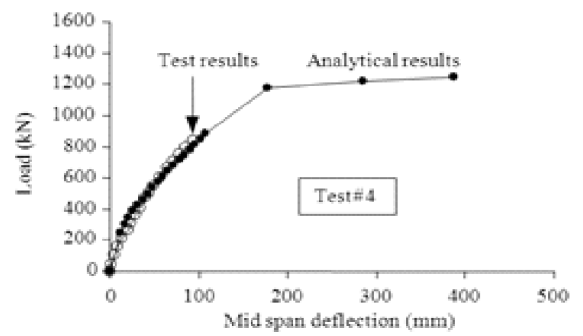

(b)

(a)

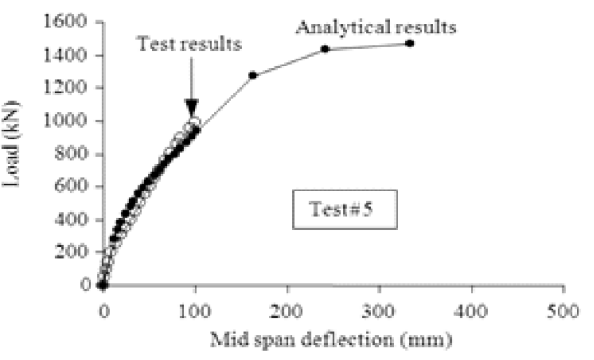

(c)

Fig. 10: Load-mid span deflection relationship of Test 3, 4 and 5 


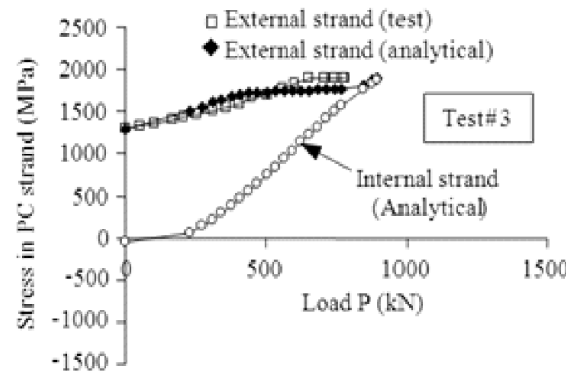

(a)

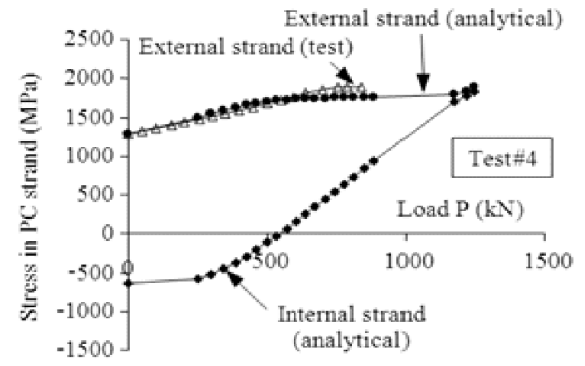

(b)

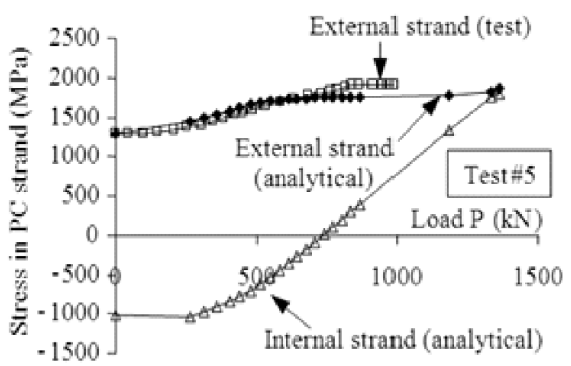

(c)

Fig. 11: Load-stress in PC strand relationship at mid span section of test cycle 3, 4 and 5

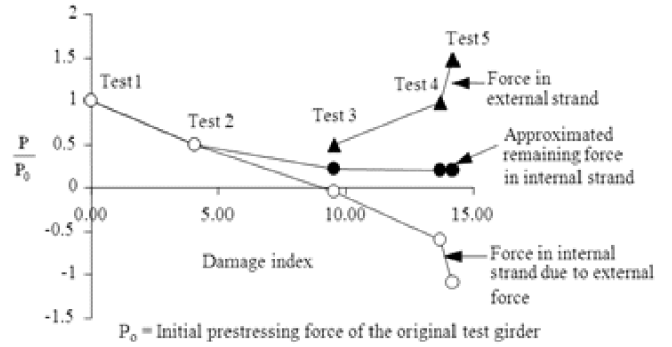

Fig. 12: Reduction of internal prestressing force in PC I girder

The relationship of damage index and reduction of internal prestressing force of the test girder is expressed by Fig. 12. It was found that reduction of internal prestressing force can be approximated directly from analytical results of the 2 nd test. In the $3^{\text {rd }}-5$ th tests, it was found that the differential of external and internal prestressing force varied linearly with the level of external prestressing force as shown by Fig. 13. This means that remaining internal prestressing force can be approximated by the average value of internal and external forces as shown by Fig. 12.

A degradation model due to overloading of the highway PC girder expressed in terms of load-mid span deflection relationship was constructed by varying the internal initial prestressing force, approximated from Fig. 12 in the analytical model, as shown by Fig. 14. Degradations of internal initial prestressing force and effective flexural rigidity due to overloading the damaged girder versus damage index are expressed in Fig. 15.

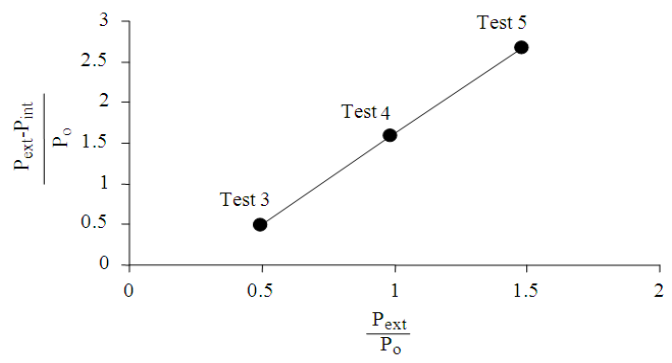

Fig. 13: Differential between external and internal prestressing force due to external prestressing force

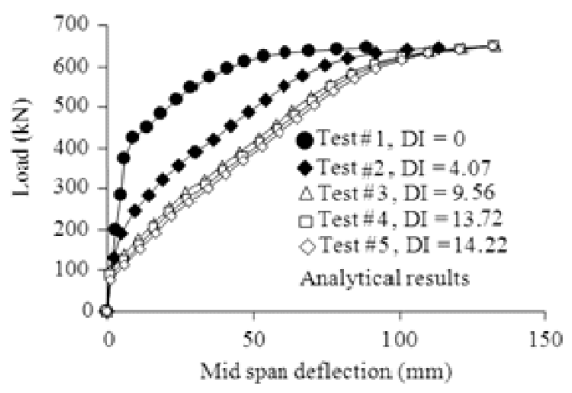

Fig. 14: Degradation model of full-scale highway girder due to overloading (analytical results)

It should be noted that the calculation of effective flexural rigidity (secant slope of $M-\phi$ diagram) was made at the same applied load or moment at the cracking stage of the original undamaged girder using Eq. 9. The analytical results 
corresponding to the $1 \mathrm{st}$ and 2 nd tests conditions were verified by the practical test results as shown by Fig. 9, but the 3rd-5th tests could not be verified directly by the practical test results. Strain data from the external strand was used to determine the load deformation relationship of equivalent damaged girder without external post-tension in the 3rd-5th tests, using the concept of load balancing proposed by Lin and Burns (1982).

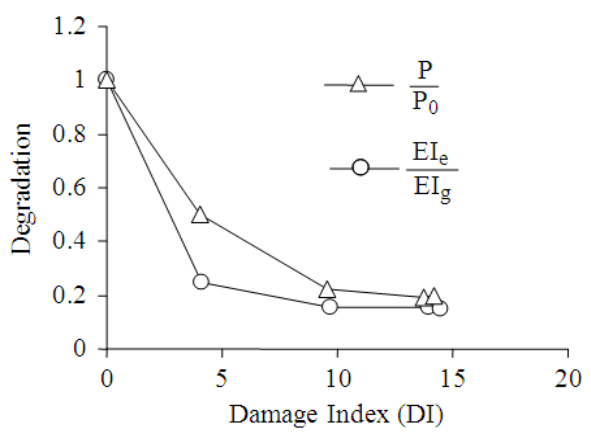

Fig. 15:Degradation of effective flexural rigidity and internal initial prestressing force of highway girder due to overloading

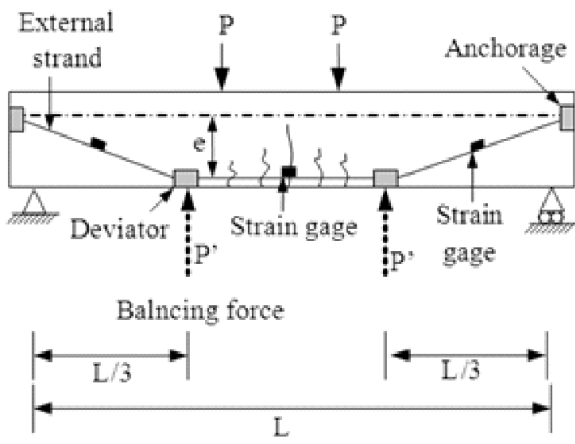

(a)

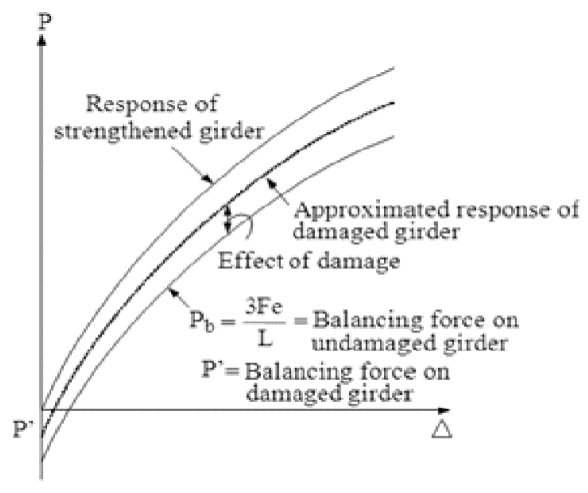

(b)

Fig. 16: Approximated load-mid span deflection relationship of equivalent damaged girder for the strengthened specimen
The load-deformation relationship of the strengthened specimen in the 3rd-5th tests (Fig. 10) shows the total effects of external post-tension and current damage for each girder test. The load balancing force produced by external posttensioning was indirectly measured by data from electrical strain gages attached to the external strands and was used in calculations of the balancing force for each step of loading. Flexural behavior of the equivalent damaged girder without strengthening for each test of the strengthened girder using the concept of load balancing is shown in Fig. 16. It should be noted that the balancing force produced by external pre-stressing force was not as fully effective for the damaged girder as for the undamaged girder. The approximate average balancing force was obtained in the same manner by determining the remaining internal pre-stressing force in pre-cast I girder (Fig. 12 and 13).

Calculated flexural behavior in terms of load vs. deflection of the test girder without external posttension in the 1 st and 2 nd tests and the equivalent response of damaged girder in the 3rd-5th tests was verified by test results as shown by Fig. 17. It was found that there was good agreement between test and analytical results so the degradation model due to overloading, which is expressed in terms of load-deformation relationship (Fig. 14), loss of internal initial prestressing force and flexural stiffness (Fig. 15) depending on damage index can be reliably applied for practical purposes.

Effects of external post tension on structural performance above the fully damaged stage of the girder after the 5th test are expressed in Fig. 18. Flexural stiffness and strength were increased above those of fully damaged girder by external force from the additional strand. It should be noted that full damage, or maximum damage index, of the test girder in this test series occurred after the end of the 5th test. In practice, this stage cannot occur by overloading due to dead and illegal truck live load plus impact factor. However, the degradation model from this study can still be used in structural evaluation to quantify the damage index and determine the appropriate external prestressing force to recover the structural performance of the damaged girder. Using the proposed analytical model, flexural behavior of degraded and strengthened girder can be reliably predicted.

The main objective of prestressed concrete is to improve structural performance in uncracked or service loading states. Ultimate moment capacity depends mainly on materials strength, steel area, concrete section and bonding between concrete and steel. In this test series, internal strands of pre-tensioned PC I girder were bonded to surrounding concrete while external strands were unbonded, so ultimate moment capacity should lie between the extreme cases. 


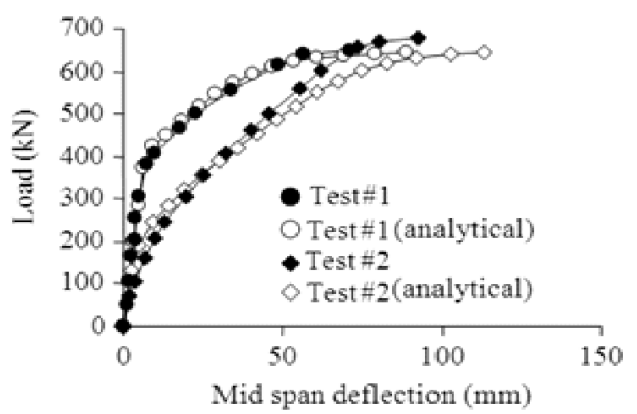

(a)

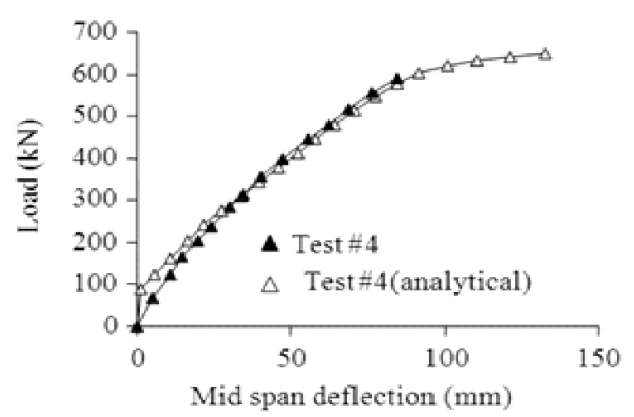

(c)

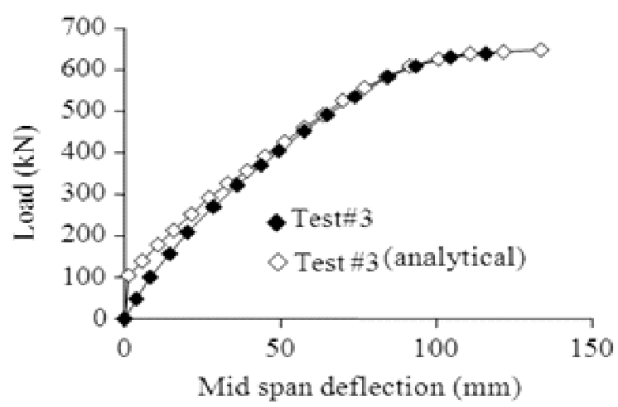

(b)

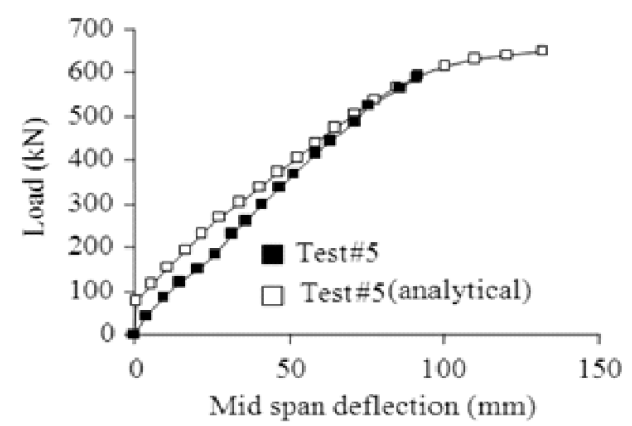

(d)

Fig. 17: Load-deflection at mid span of damaged girder

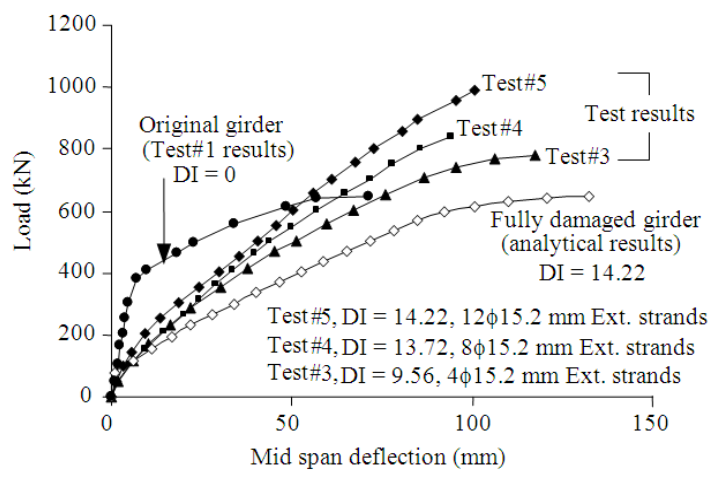

Fig. 18: Effects of external prestressing force on flexural behavior of strengthened girder

If second order effects due to incompatibility between member deformation and tendon profile at high load level close to the ultimate stage are neglected, the load-deflection diagram of the strengthened specimen in this test series as predicted by the simplified analytical model is shown in Fig. 19a. It was found that flexural strength of the specimen with external post-tension increased depending on level of external prestressing forces while ductility decreased. Stiffness, strength and ductility must be considered in design of girder strengthening. Load deflection of strengthened girder from analytical data in Fig. 19a shows that sufficient ductility was found for all strengthened specimens.
Parametric studies can be performed by the simplified analytical model and the results are shown in Fig. 19b-d. It was found that significant improvement of flexural stiffness and strength by external post-tension strongly depends on damage index and external prestressing force. Maximum damage index in this test series was quite large so a high external prestressing force was required to recover the structural performance of the damaged girder. In practice, overload causing damage can be slightly higher than the cracking load leading to low damage index so the lower external prestressing force to be strengthened is required. Remaining internal prestressing force depending on damage index can be approximated by the degradation model in Fig. 12 and 15. A high level of external prestressing force for strengthening is required for a high level of damage. Flexural stiffness is effectively recovered by low prestressing force from external posttensioning for low damage index while ultimate moment capacity is strongly dependent on the area of external steel strands.

From experimental and analytical data in this study, it was found that improvement of structural performance due to external post-tensioning in terms of flexural stiffness, strength and recovered permanent deformation can be expressed in Fig. 20. It should be noted that uplift or balancing moment in the $\mathrm{x}$ axis, external or internal prestressing force multiplied by eccentricity, is more appropriate than prestressing force since it accounts for the effect of tendon eccentricity. 


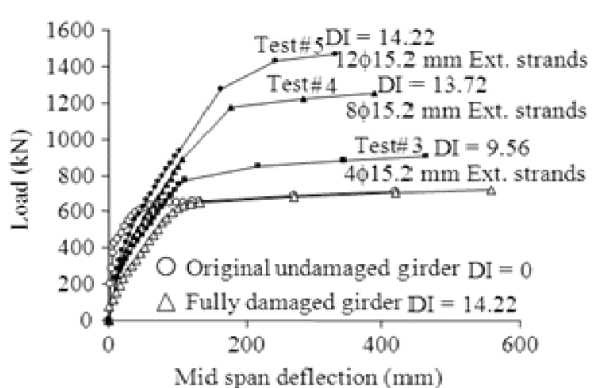

(a)

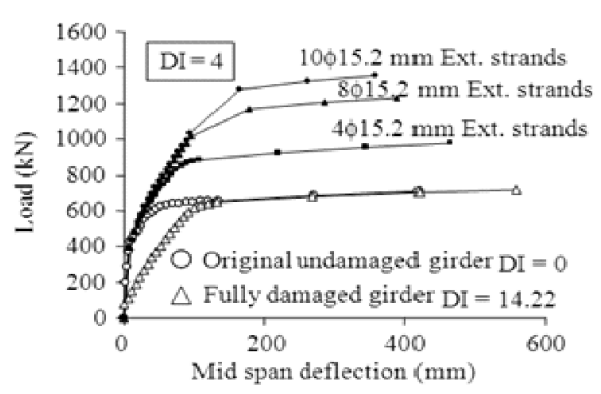

(c)

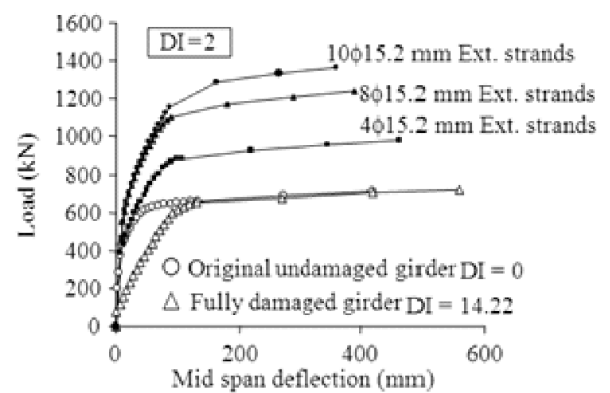

(b)

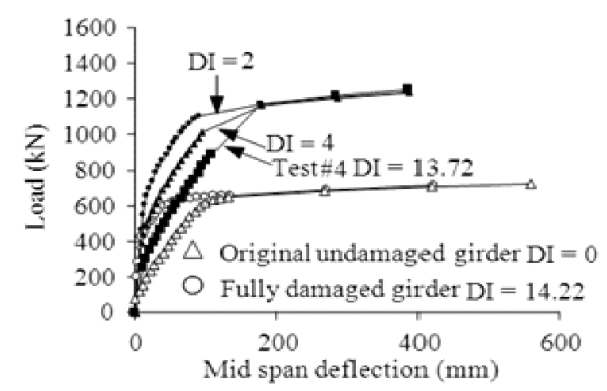

(d)

Fig. 19: Load-deflection at mid span of damaged girder and strengthened girder from analytical results. (a) Response of strengthened girder in this test series; (b) Response of strengthened girder for DI = 2; (c) Response of strengthened girder DI $=4$; (d) Response of the girder strengthened by $8 \phi 15.2 \mathrm{~mm}$ ext. strand for difference damage index

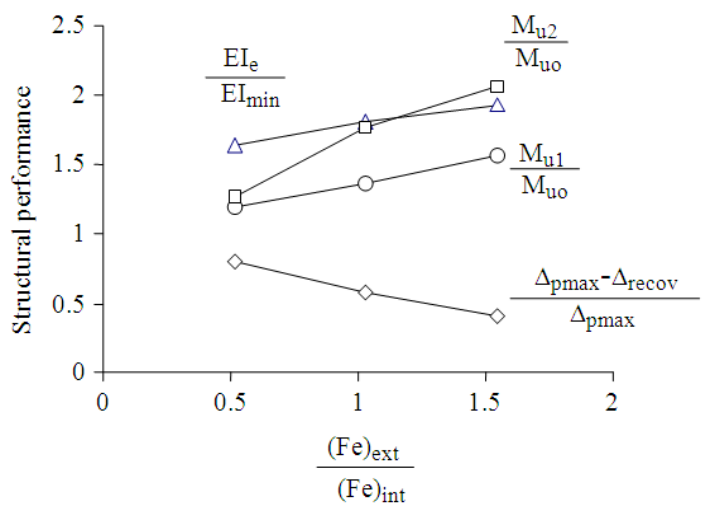

Fig. 20: Effects of external post-tension on structural performance of damaged girder

Ultimate moment capacity in Fig. 20 from test data $\left(\mathrm{M}_{\mathrm{u} 1}\right)$ is the maximum moment carried by the test girder at the same maximum deflection as in the 5 th test and ultimate moment capacity $\left(\mathrm{M}_{\mathrm{u} 2}\right)$ from the analytical model (Fig. 19) is the moment to cause crushing of concrete in the top fiber of the mid span section. Additional symbols in Fig. 20 can be described as follows; $\Delta_{\text {pmax }}$ is maximum permanent deflection at the end of the 5th test cycle, $\Delta_{\text {recov }}$ is recovered permanent deflection due to external prestressing, $\mathrm{EI}_{\mathrm{e}}$ is the effective flexural rigidity, $\mathrm{EI}_{\min }$ is the effective flexural rigidity of fully damaged girder and $\mathrm{M}_{\mathrm{u} 0}$ is the ultimate moment capacity of the reference girder from the analytical result.

It is recommended that external tendon profile should be placed at the locations which produce maximum balancing force or moment along the girder. Adequate and appropriate location of deviators should be provided to reduce second order effects on flexural strength of strengthened girder. Repairing of a wide crack is standard practice after strengthening to protect the concrete material from deterioration and steel corrosion due to penetration of moisture and aggressive chemical substances from the severe environment.

\section{CONCLUSION}

Full scale tests were performed to study the damage due to overloading of a highway bridge girder specimen. External post-tension was applied to recover the structural performance of the damaged test girder by varying external prestressing forces. The following conclusions can be made:

- A degradation model of full scale highway PC girder due to overloading is proposed based on both experimental and analytical data. The model was described by degradation of flexural behavior of the test girder in terms of load- 
deformation relationships, loss of internal initial prestressing force in pre-cast PC girder and loss of flexural stiffness in terms of effective flexural rigidity $\left(\mathrm{EI}_{\mathrm{e}}\right)$. Such degradations depended on the level of damage which can be expressed in terms of damage index (the ratio of permanent deformation divided by crack deformation of the reference undamaged girder)

- The degraded specimen was strengthened by means of external post-tension. Appropriate external prestressing forces and tendon eccentricity used in recovering the structural performance of degraded girder depended on damage index. High level of external prestressing force was required for the degraded girder with high damage index. The most important key factors which must be considered in prestressed concrete bridge strengthening are flexural stiffness, strength and ductility

- The proposed simplified analytical model, using moment-curvature relationship (M- $\phi$ diagram) and concept of flexural rigidity $\left(\mathrm{EI}_{\mathrm{e}}\right)$, in this study can be used to predict flexural behavior of both degraded and strengthened test girders

\section{ACKNOWLEDGEMENT}

We are grateful to the Center of Materials Testing Khonkaen University for supporting this research.

\section{REFERENCES}

Alkhairi, F.M. and A.E. Naaman, 1993. Analysis of beams prestressed with unbonded tendons or external tendons. J. Struct. Eng., 199: 2680-2700. DOI: 10.1061/(ASCE)07339445(1993)119:9(2680)

Beer, F.P. and E.R. Johnston, 1985. Mechanics of Materials. 1st Edn., McGraw-Hill, New York, ISBN: 0075485788, pp: 610.

Branson, D.E., 1977. Deformation of Concrete Structures. 1st Edn., McGraw-Hill Inc., US., ISBN: 10: 007007240X, pp: 576.
Diep, B.K. and H. Umehara, 2002. Non-linear analysis of externally prestressed concrete beams. Elect. J. Struct. Eng., 2: 85-86. http://www.civag.unimelb.edu.au/ejse/Archives/ Fulltext/200201/07/20020107.pdf

Hsieh, Y.Y., 1988. Elementary Theory of Structures. 3rd Edn., McGraw-Hill, New York, ISBN: 0132615207, pp: 154.

Lin, T.Y. and N.H. Burns, 1982. Design of Prestressed Concrete Structures. 3rd Edn., Wiley, New York, ISBN: 0471890588, pp: 646.

Mattock, A.H., 1979. Flexural strength of prestressed concrete sections by programmable calculator. PCI J., $24: \quad 32-54$. http://www.pci.org/pdf/publications/journal/1979 /January-February/JL-79-JANUARYFEBRUARY-3.pdf

Matupayont, S., 1995. Flexural behaviors of externally prestressed concrete beams. Ph.D. Thesis, Saitama University.

Naaman, A.E. and A. Siriaksorn, 1979. Serviceability based design of partially prestressed beams: Parti: Analytical formulation. J. Prestressed Concrete Inst., 24: 64-89.

Park, R. and T. Paulay, 1975. Reinforced Concrete Structures. 1st Edn., Wiley, New York, ISBN: 10: 0471659177, pp: 800.

Popovics, S., 1970. A review of stress-strain relationships for concrete. J. Proc., 67: 243-248. http://www.concrete.org/PUBS/JOURNALS/OL JDetails.asp?Home $=$ JP\&ID=7266

Tan, K.H. and C.K. Ng, 1998. Effects of shear in externally prestressed beams. Struct. J., 95: 116-128. http://www.concrete.org/PUBS/JOURNALS/OL JDetails.asp?Home $=$ SJ \&ID=532

Tan, K.W and C.K. Ng, 1997. Effect of deviators and tendon configuration on behavior of externally prestressed beams. ACI Struct. J., 94: 13-22. http://cat.inist.fr/?aModele $=$ afficheN\&cpsidt $=26$ 07591 